\title{
Genetic and environmental effects on exhaled nitric oxide and airway responsiveness in a population-based sample of twins
}

\author{
M.B. Lund*, J. Kongerud*, W. Nystad" , J. Boe* and J.R. Harris ${ }^{\#}$
}

ABSTRACT: Elevated levels of exhaled nitric oxide (eNO) and airway hyperresponsiveness are intermediate phenotypes of asthma. Using population-based data collected from a sample of twins, the present authors estimated the relative contribution of genes, family environment and nonshared environmental influences to variations in eNO and airway responsiveness (AR). In addition, the genetic and environmental sources of covariation between these two asthma-related phenotypes were investigated.

The study population comprised a random sample of 377 adult twins identified through the Norwegian Twin Registry. The main outcome variables were eNO and AR to methacholine.

Genetic effects accounted for $60 \%$ of the variation in eNO. Family environment accounted for $30 \%$ of the variation in $A R$, while nonshared environmental influences explained the remaining variation for both measures. For both eNO and AR, there were significant regression effects for atopy and smoking. The small, but significant association between eNO and AR was primarily explained by genetic factors. Sub-analyses restricted to atopic and nonsmoking twins strengthened the observation.

In conclusion, variations in exhaled nitric oxide and airway responsiveness appear to be explained by different genetic and environmental variance structures. Variation in exhaled nitric oxide is explained by genetic and nonshared environmental effects, whereas an environmental model best explains the variation in airway responsiveness. Common genetic effects explain the small but significant association between exhaled nitric oxide and airway responsiveness.

KEYWORDS: Airway responsiveness, asthma phenotypes, epigenetics, exhaled nitric oxide, methacholine, twins

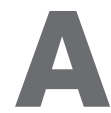
sthma is a chronic inflammatory disorder presenting a wide spectrum of clinical manifestations. Twin and family studies report genetic and environmental influences on asthma aetiology $[1,2]$ and molecular approaches provide insight into the genes associated with asthma and the related phenotypes [3, 4]. Regions linked to these phenotypes have been detected both in candidate gene studies and genome screens $[5,6]$. One approach designed to help elucidate issues of aetiology is to study the genetic and environmental sources of variation and covariation in asthma-related phenotypes.

Elevated levels of exhaled nitric oxide (eNO) and airway hyperresponsiveness (AHR) are intermediate phenotypes (biomarkers) associated with asthma but neither is specific to the disease.
eNO is a marker of airway inflammation recognised as a critical component of the asthmatic phenotype [7]. Levels of eNO are increased in asthmatics [8] and the measurement of eNO is advocated as a tool to discriminate asthmatics from nonasthmatics [9]. Levels of eNO correlate with markers of asthmatic inflammation, such as sputum and serum eosinophils [10, 11]. An association between eNO and eosinophilic inflammation has been reported in bronchial biopsies of patients with atopic asthma [12]. The relationship between eNO and airway responsiveness (AR) is controversial and conflicting results have been published [13, 14].

Measuring AR is advocated in population studies of asthma due to its close relationship with the underlying mechanisms of the disease [15].

\section{AFFILIATIONS}

*Dept of Respiratory Medicine, Rikshospitalet University Hospital, and

"Division of Epidemiology, Norwegian Institute of Public Health, Oslo, Norway.

CORRESPONDENCE

M.B. Lund

Dept of Respiratory Medicine Rikshospitalet University Hospital $\mathrm{N}-0027$ Oslo

Norway

Fax: 4723073917

E-mail: may.brit.lund@

rikshospitalet.no

Received:

April 142005

Accepted after revision:

October 182006

STATEMENT OF INTEREST

Statements of interest for all authors of this manuscript can be found at www.erj.ersjournals.com/misc/ statements.shtml

European Respiratory Journal Print ISSN 0903-1936 Online ISSN 1399-3003 
However, there is no clear evidence of a close relationship between AHR and asthmatic inflammation [16]. Autonomic dysfunction or airway wall remodelling may help explain inter-individual variability in AR [17, 18].

A few genetically informative epidemiological studies have assessed AR and atopy [19-21], but the heritability of eNO has not yet been explored. A key question is whether measures of eNO and AR are related and, if so, whether this relationship is explained by common genetic and/or environmental pathways. The purpose of the present study was to estimate the relative contribution of genes and environment to variation in eNO and AR using population-based data from a sample of young twin adults. A further aim was to investigate the genetic and environmental sources of covariation between these two asthma-related phenotypes.

\section{METHODS}

\section{Study population}

The clinical data were collected as a sub-study to the study of twins carried out at the Norwegian Institute of Public Health (Oslo, Norway) [22]. All twins born in Norway during the period 1967-1979 were identified through the Norwegian Birth Registry. The twins who participated in the current study were sampled from respondents to a questionnaire study conducted in 1998. The questionnaire was sent to 12,701 like- and unlikesexed twins aged 18-31 yrs. Responses were obtained from $3,334(69 \%)$ complete pairs. Zygosity was determined on the basis of seven questions previously validated to correctly categorise $>97 \%$ of the twins in another Norwegian study [23]. The sample and zygosity classification procedure are described elsewhere [23, 24]. A random sample of twins living within a 2$\mathrm{h}$ transportation radius from Oslo was invited to participate in the present study. Exclusion criteria were pregnancy and medical conditions that might interfere with carrying out the tests. In total, out of 1,446 twins (723 pairs) selected, 643 twins were willing to participate. The clinical study was completed on 377 twins comprising 171 pairs and 35 twins whose co-twin was not tested. The participants in the clinical study did not differ from the nonparticipants with respect to sex, age or zygosity. The regional medical ethics committee approved the study and written informed consent was obtained from all subjects.

\section{Measures}

The main outcomes were concentrations of eNO and AR to methacholine. All subjects had to be free from respiratory infections 6 weeks prior to testing. Subjects with asthma or hay fever were tested during the nonpollen season (September March). Those who used antihistamines or long- or shortacting $\beta_{2}$-agonists were instructed to withhold medication for 1 week, $12 \mathrm{~h}$ and $8 \mathrm{~h}$, respectively, before testing. Regular use of inhaled corticosteroids was recorded. Ex-smokers were those who had stopped smoking $\geqslant 1 \mathrm{yr}$ before study commencement. Current smokers were asked to refrain from smoking on the test day.

\section{eNO}

eNO was measured by a chemiluminescence analyser (LR 2000; Logan Research, Rochester, UK) adapted for online recording of nitric oxide (NO) concentrations. The sampling flow rate of the analyser was set to $250 \mathrm{~mL} \cdot \mathrm{min}^{-1}$ for all measurements. The analyser was calibrated daily using certified NO mixtures (100 ppb) in nitrogen (BOC Special Gases, Guildford, UK). Ambient NO level was recorded before each individual test. The measurements were performed in accordance with recommendations outlined by the European Respiratory Society (ERS) [25]. End-expiratory NO values were measured at the plateau level of the last part of the exhalation curve. Three technically acceptable measurements were obtained and the mean value reported. In order to normalise the distribution, the natural logarithm of eNO scores was used.

\section{Baseline lung function}

Lung function was assessed by dynamic spirometry (Master Screen Body; Erich Jaeger, Würzburg, Germany). The spirometer was calibrated daily using a 1 L-syringe. The measurements were performed in accordance with guidelines recommended by the American Thoracic Society [26]. The recorded variables were forced vital capacity (FVC), forced expiratory volume in one second (FEV1), forced expiratory flow at $50 \%$ of $\mathrm{FVC}$ and $\mathrm{FEV} 1 / \mathrm{FVC} \times 100$. The lung function variables were expressed in absolute values and as percentage of predicted, using the reference values recommended by the ERS [27].

\section{AR}

A methacholine provocation test was performed in subjects with baseline FEV $1>70 \%$ of predicted who did not decrease their FEV 1 by $>10 \%$ of the post-isotonic saline value. The test was performed with a standard dosimeter method in line with ERS guidelines [28]. In brief, the automatic tidal-volumetriggered equipment with a calibrated fixed output (APS; Erich Jaeger) was programmed to deliver a maximum cumulative dose of $19.89 \mu \mathrm{mol}$ methacholine in six or seven increments, starting with $0.255 \mu \mathrm{mol}$ and $0.051 \mu \mathrm{mol}$ in nonasthmatic and asthmatic individuals, respectively. FEV1 was measured $60 \mathrm{~s}$ after each dose. The test was terminated if the decline in FEV1 was $>20 \%$ of post-diluent value. AR to methacholine was recorded as the cumulative dose which caused a $20 \%$ fall in FEV1 (PD20). The dose-response slope (DRS) was calculated as the maximal percentage fall in FEV1 divided by the cumulative dose [28]. AHR was defined as PD20 $<7.8 \mu \mathrm{mol}$ [28]. In order to normalise the distribution, the natural logarithm of the DRS scores was used.

\section{Atopy}

Atopy was assessed from skin-prick tests (Soluprick SQ; ALK, Hùrsholm, Denmark) to eight common allergens (cat, dog, horse, timothy grass, birch, mugwort (Artemisia vulgaris), Cladosporium herbarum and Dermatophagoides pteronyssinus) in accordance with European guidelines [29]. Atopy was defined as a positive response (weal diameter $\geqslant 3 \mathrm{~mm}$ and greater than the negative control) to at least one allergen.

\section{Analyses}

Structural equation modelling using Mx [30] was conducted to estimate genetic and environmental influences on variances and covariances. These models are widely used to analyse twin data [31]. Briefly, four general sources of variance and covariance are estimated: 1 ) additive genetic factors (A), which reflect the summed effect of alleles at each contributing genetic locus; 2) nonadditive genetic factors (D for "dominance"), 
which reflect the summed effect of dominance deviations at all contributing loci; 3) common environment (C), which represents all sources of shared environmental experiences and exposures that contribute to within-pair resemblance; and 4) nonshared environment (E), which represents all sources of unique experiences and exposures that cause within-pair differences. Examples of shared environments include in utero effects, parental smoking and other conditions in the rearing home that could affect the development of asthma, such as house dust mites, mould, etc., as well as macro-level factors that are implicated in health, such as socioeconomic status. Examples of nonshared environments or exposures are discordance for smoking and differences in diseases and occupational exposures. Univariate models were analysed to test the significance of the covariates sex, age, smoking and atopy. Next, the genetic and environmental variance structure of each measure was estimated. In these analyses, each model comprised a set of simultaneous linear equations specifying the biometrical expectations for the genetic and environmental contributions to the variance-covariance structure in the data for identical (MZ) and fraternal (DZ) twins. Among MZ pairs, genetic effects are perfectly correlated, while among DZ pairs additive and dominant genetic effects are correlated 0.5 and 0.25 , respectively. Common environmental effects are perfectly correlated in both zygosity groups, whereas influences due to nonshared environmental effects are uncorrelated. Fixed effects of sex, smoking status, age and a positive score for atopy were incorporated into the means model.

The relationship between eNO and AR was then analysed using a bivariate ACE model that decomposed the covariance between these measures into correlated genetic $\left(r_{\mathrm{G}}\right)$, shared environmental $\left(r_{\mathrm{C}}\right)$ and nonshared environmental $\left(r_{\mathrm{E}}\right)$ pathways. A full model estimating all three latent factor correlations was analysed first and subsequent models tested for the significance of each correlation by dropping it from the model.

The raw data option in Mx calculates minus twice the loglikelihood (-2LL) of the data but does not provide an overall measure of fit. Model comparisons were conducted using the likelihood ratio Chi-squared test $\left(\Delta \chi^{2}\right)$ and difference in degrees of freedom $(\Delta \mathrm{df})$ to compare the relative fit of nested models and the Akaike Information Criterion (AIC), calculated as:

$$
\mathrm{AIC}=\Delta \chi^{2}-2 \Delta \mathrm{df}
$$

which combines parsimony and fit.

Prior to model specification, the pattern of MZ versus DZ intraclass correlations were inspected to determine which factors (A, C, D, E) were important to parameterise. Greater MZ values than $D Z$ values indicate genetic effects and $M Z$ correlations that exceed twice the DZ value suggest nonadditive (D) effects. Common environmental effects are indicated if the DZ correlation is greater than twice the MZ correlation [31].

\section{RESULTS}

\section{Clinical characteristics and measures}

Table 1 presents clinical characteristics of the sample by sex. Females comprised $60 \%$ of the study population. Both sexes were comparable with respect to age, body mass index, smoking habits, atopy and lung function. The prevalence of AHR was higher in females than in males (26 versus 13\%, $p=0.003$ ), whereas the sexes were comparable with respect to levels of eNO. There were no significant differences across zygosity for any of the measures. The prevalence of AHR was higher in atopic than in nonatopic individuals (29 versus 16\%, $\mathrm{p}=0.004)$. Levels of eNO were increased among nonsmoking subjects with atopy compared with those without atopy (7.7 ppb (1.8) versus $6.1 \mathrm{ppb}(1.6), \mathrm{p}=0.001)$. There was a positive correlation between DRS and eNO $(r=0.14, p=0.006)$. The correlation was greater in nonsmokers $(\mathrm{r}=0.27, \mathrm{p}<0.001)$ and particularly so in nonsmoking atopic subjects $(r=0.43$, $p<0.001)$. The prevalence of self-reported asthma was $7.8 \%$, which is highly similar to the prevalence $(8.0 \%)$ reported in the study population from which the sample was drawn $(3,300$ pairs of twins).

\section{Univariate results for eNO and $A R$}

Tests of the modelled covariates revealed no effect for age. For eNO there were significant regression effects for smoking (change in Chi-squared tests between nested models with one degree of freedom $\left.\left(\Delta \chi_{(1)}^{2}\right)=18.71, \mathrm{p}<0.001\right)$ and atopy $\left(\Delta \chi_{(1)}^{2}=9.99\right.$, $\mathrm{p}<0.01)$. AR regressions were significant for $\operatorname{sex}\left(\Delta \chi_{(1)}^{2}=14.36\right.$, $\mathrm{p}<0.001)$, smoking $\left(\Delta \chi_{(1)}^{2}=16.09, \quad \mathrm{p}<0.001\right) \quad$ and atopy $\left(\Delta \chi^{2}{ }_{(1)}=9.68, \mathrm{p}<0.01\right)$. The intra-class correlations for the MZ and DZ twins were 0.57 and 0.28 for the $\log$ score of eNO and 0.35 and 0.32 for the log score of DRS, respectively. These values suggest that different patterns of genetic and environmental influences explain the variations in eNO and AR. Specifically,

\begin{tabular}{|c|c|c|c|}
\hline \multirow[t]{2}{*}{ TABLE 1} & \multicolumn{3}{|c|}{$\begin{array}{l}\text { Clinical characteristics, lung function, airway } \\
\text { responsiveness and levels of exhaled nitric oxide } \\
\text { (eNO) by sex }\end{array}$} \\
\hline & Male & Female & Total \\
\hline Subjects $\mathrm{n}$ & $149(40)$ & $228(60)$ & 377 (100) \\
\hline Zygosity MZ:DZ & 77 (52):72 (48) & $131(57): 97(43)$ & 208 (55):169 (45) \\
\hline Age yrs & 28 (20-33) & 28 (20-33) & $28(20-33)$ \\
\hline BMI $\mathbf{k g} \cdot \mathrm{m}^{-2}$ & $24 \pm 3$ & $23 \pm 4$ & $23 \pm 4$ \\
\hline \multicolumn{4}{|l|}{ Smoking } \\
\hline Never & $91(61)$ & $139(61)$ & $230(61)$ \\
\hline Ex & $14(9)$ & $21(9)$ & $35(9)$ \\
\hline Current & $44(30)$ & $68(30)$ & $112(30)$ \\
\hline Atopy & $54(36)$ & 79 (35) & $133(35)$ \\
\hline FVC \% pred & $109 \pm 10$ & $109 \pm 11$ & $110 \pm 10$ \\
\hline FEV $1 \%$ pred & $107 \pm 11$ & $106 \pm 11$ & $106 \pm 11$ \\
\hline FEV $_{1} \%$ & $82 \pm 7$ & $84 \pm 7$ & $83 \pm 7$ \\
\hline FEF $50 \% \%$ pred & $90 \pm 24$ & $88 \pm 20$ & $89 \pm 22$ \\
\hline $\mathrm{AHR}^{\#}$ & $19(13)$ & $59(26)^{\bullet}$ & $78(21)$ \\
\hline $\mathrm{eNO}^{+} \mathrm{ppb}$ & $6.5 \pm 1.6$ & $5.9 \pm 1.7$ & $6.1 \pm 1.7$ \\
\hline Nonsmokers & $7.1 \pm 1.5$ & $6.4 \pm 1.7$ & $6.7 \pm 1.7$ \\
\hline Smokers & $5.4 \pm 1.9$ & $4.8 \pm 1.5$ & $5.3 \pm 1.7$ \\
\hline
\end{tabular}

Data are presented as $n(\%)$, median (range) or mean $\pm S D$. MZ: identical twins; DZ: fraternal twins; BMI: body mass index; FVC: forced vital capacity; \% pred: $\%$ predicted; FEV1: forced expiratory volume in one second; FEV1\%: FEV $1 /$ FVC $\times 100$; FEF $50 \%$ : forced expiratory flow at $50 \%$ of FVC; AHR: airway hyperresponsiveness; ppb: parts per billion. ${ }^{\#}$ : defined as a provocative dose causing a $20 \%$ fall in FEV $1<7.8 \mu \mathrm{mol},{ }^{\circ}: p=0.003$ compared with males; ${ }^{+}$ geometric mean $\pm \mathrm{SD}$ 
TABLE 2 Genetic and environmental variance component estimates for airway responsiveness

\begin{tabular}{|c|c|c|c|c|c|c|c|c|}
\hline Model & A & C & E & $-2 \mathrm{LL}$ & $\Delta \chi^{2}$ & $\Delta d \mathbf{d f}$ & $\mathrm{p}$-value & AIC \\
\hline ACE & $0.00(0.00-0.44)$ & $0.30(0.00-0.43)$ & $0.70(0.55-0.85)$ & 801.65 & & & & \\
\hline CE & & $0.30(0.15-0.43)$ & $0.70(0.57-0.85)$ & 801.65 & 0.00 & 1 & 0.99 & -2.00 \\
\hline E & & & $1.00(1.00-1.00)$ & 817.00 & 15.35 & 2 & $<0.01$ & 11.35 \\
\hline
\end{tabular}

Data are presented as $95 \%$ confidence interval and goodness of fit statistics. A: additive genetic variance; C: variance of common environment; E: variance of nonshared environment; LL: log-likelihood; $\Delta \chi^{2}$ : change in Chi-squared tests between nested models; $\Delta$ df: difference in degrees of freedom between nested models; AlC: Akaike's information criteria

genetic and nonshared environmental effects are indicated for variation in eNO, whereas shared and nonshared environmental influences seem more important for variation in AR. Given the lack of evidence for genetic dominance, ACE models and submodels were tested for both measures. Results including the genetic and environmental variance estimates, 95\% confidence intervals (CI) and model fit statistics are presented in tables 2 and 3. For AR, the base ACE model estimated genetic effects (A) to be zero. Testing nested sub-models revealed that dropping $\mathrm{A}$ $\left(\Delta \chi_{(1)}^{2}=0.00, \mathrm{p}=0.99\right)$ or $\mathrm{C}\left(\Delta \chi_{(1)}^{2}=1.24, \mathrm{p}=0.27\right)$ did not significantly affect the model fit, but that one of these sources of shared effects (A or C) must be retained. The E-only model showed a significant reduction in fit (change in Chi-squared tests between nested models with two degrees of freedom $\left.\left(\Delta \chi_{(2)}^{2}\right)=15.35, \mathrm{p}<0.01\right)$. The completely environmental model $(\mathrm{CE})$ is the most consistent with the pattern of intra-class correlations and also yielded the lowest AIC value. Accordingly, a CE model best explains variation in $\mathrm{AR}$, with common effects accounting for $30 \%$ of the variation and nonshared environmental factors explaining the remaining variation. In contrast, the results for eNO revealed highly significant genetic effects. Dropping A from the model resulted in a significant deterioration in fit $\left(\Delta \chi_{(1)}^{2}=10.13, p \leqslant 0.01\right)$. However, there was no effect of shared environment $\left(\Delta \chi^{2}{ }_{(1)}=0\right)$ as evidenced by no change in -2LL when dropping $C$ from the model. The AE model showed the best fit according to AIC with genetic and nonshared environmental influences for 60 and $40 \%$ of the variation, respectively.

Bivariate analyses of the relationship between eNO and AR The association between eNO and AR is weak but significant $(\mathrm{r}=0.14, \mathrm{p}=0.006)$. The cross-twin cross-trait correlations (eNO in twin A with AR in twin B) were 0.23 for $\mathrm{MZ}$ and 0.04 for $\mathrm{DZ}$ twins. This pattern suggests that genetic effects contribute importantly to the association between eNO and AR. Bivariate analyses revealed that a model with no covariation was unfit for the data. Therefore, tests of the importance of each source of covariation $\left(r_{\mathrm{G}}, r_{\mathrm{C}}\right.$ and $\left.r_{\mathrm{E}} ; \mathrm{M} 1\right)$ were conducted and results are listed in table 4. Dropping the genetic correlation (M2) resulted in a deterioration in fit, whereas dropping the shared environmental (M3) or nonshared environmental (M4) correlations did not affect the model fit. Retaining the genetic correlation only and dropping both $r_{\mathrm{C}}$ and $r_{\mathrm{E}}$ (M5) does not affect the fit and yields the lowest AIC value. This is further supported by the results of dropping $r_{\mathrm{G}}$ and $r_{\mathrm{E}}(\mathrm{M} 6)$ and $r_{\mathrm{G}}$ and $r_{C}$ (M7), which show a deterioration in fit as a result of the exclusion of $r_{\mathrm{G}}$. The significance of $r_{\mathrm{G}}$ was even greater when the base model excluded $r_{\mathrm{E}}$ (not tabled), dropping $r_{\mathrm{G}}$ resulted in a $\Delta \chi^{2}=5.818, \Delta \mathrm{df}=1$ and $\mathrm{p}=0.016$; whereas dropping $r_{\mathrm{C}}$ hardly altered the $-2 \mathrm{LL}\left(\Delta \chi^{2}=0.544, \Delta \mathrm{df}=1, \mathrm{p}=0.461\right)$. Collectively, results showing a significant change in fit only when genetic sources of covariation are excluded suggest that association between eNO and AR is primarily explained by common genetic effects.

\section{DISCUSSION}

This population-based study of young adult twins revealed that the variation in eNO and AR appeared to be explained by different genetic and environmental variance structures. Whereas variation in eNO was explained by genetic and environmental factors, variation in AR was mainly attributed to environmental effects. The small but significant association between eNO and AR was primarily explained by common genetic factors. This finding may seem inconsistent given that

TABLE 3 Genetic and environmental variance component estimates for exhaled nitric oxide

\begin{tabular}{|c|c|c|c|c|c|c|c|c|}
\hline ACE & $0.60(0.28-0.71)$ & $0.00(0.00-0.26)$ & $0.40(0.29-0.55)$ & 449.06 & & & & \\
\hline CE & & $0.42(0.28-0.53)$ & $0.58(0.47-0.72)$ & 459.18 & 10.13 & 1 & $<0.01$ & 8.13 \\
\hline E & & & $1.00(1.00-1.00)$ & 490.00 & 40.94 & 2 & 0.00 & 36.94 \\
\hline
\end{tabular}

Data are presented as $95 \%$ confidence interval and goodness of fit statistics. A: additive genetic variance; C: variance of common environment; $E$ : variance of nonshared environment; LL: log-likelihood; $\Delta \chi^{2}$ : change in Chi-squared tests between nested models; $\Delta \mathrm{df}$ : difference in degrees of freedom between nested models; AlC: Akaike's information criteria. 
TABLE 4 Results from testing alternative models of covariation between exhaled nitric oxide and airway responsiveness

\begin{tabular}{|c|c|c|c|c|c|c|}
\hline \multicolumn{2}{|c|}{ ACE model } & \multicolumn{5}{|c|}{ Fit statistics } \\
\hline Model number & Sources of covariation & $-2 L L$ & $\Delta \chi^{2}$ & $\Delta \mathrm{df}$ & $\mathrm{p}$-value & AIC \\
\hline M1 & $r_{\mathrm{G}}, r_{\mathrm{C}}, r_{\mathrm{E}}$ & 1235.94 & & & & \\
\hline M2 & $r_{C}, r_{E}$ & 1239.80 & 3.86 & 1 & 0.05 & 1.86 \\
\hline М3 & $r_{\mathrm{G}}, r_{\mathrm{E}}$ & 1236.39 & 0.45 & 1 & 0.51 & -1.56 \\
\hline M6 & $r_{\mathrm{C}}$ & 1241.86 & 5.92 & 2 & 0.05 & 1.92 \\
\hline M7 & $r_{\mathrm{E}}$ & 1244.74 & 8.80 & 2 & 0.01 & 4.80 \\
\hline
\end{tabular}

A: additive genetic variance; C: variance of common environment; E: variance of nonshared environment; LL: log-likelihood; $\Delta \chi^{2}$ : change in Chi-squared tests between nested models; $\Delta$ df: difference in degrees of freedom between nested models; AlC: Akaike's information criteria; $r_{G}$ : genetic correlation; $r_{C}$ : correlation between shared environmental influences; $r_{E}$ : correlation between nonshared environmental influences.

an environmental model best described the AR data. However, the CI were wide in the univariate results and power to detect potential genetic effects is increased in the bivariate analysis.

Genetic studies using the twin-design are based upon the assumption that twins are representative of the general population for the outcomes being studied. Comparisons with prevalence rates from non-twin population-based Norwegian surveys suggest that the twin data in the current study are representative of the general population with respect to atopy, AHR [32] and smoking habits [33]. The prevalence of atopy was $35 \%$. Similar prevalence rates have been reported in other Scandinavian studies of young adults and adolescents [32, 34]. In the current study, the $21 \%$ prevalence of AHR is in line with data previously reported from a population survey of Norwegian adolescents [32]. The observation that AHR is more prevalent in females than in males has also been reported in other Scandinavian studies $[35,36]$. No evidence was found of zygosity differences in the prevalence of any of the clinical measures. Given the similarity in the reported prevalence of asthma between the sample who participated in the clinical testing and the population-based sample of twins responding to the main questionnaire, it is unlikely that selection bias presents a major problem in the present study.

In recent years, eNO has become recognised as an important component of the asthmatic phenotype [7]. Endogenous NO is derived from L-arginine by the enzyme NO synthase (NOS), of which at least three distinct isoforms have been identified. Two of these are constitutively expressed (NOS1 and NOS3), while a third (NOS2) is inducible and shows increased expression in inflammatory disorders. Genetic polymorphisms of all three NOS isoforms have been identified and associations have been reported between NOS1 gene polymorphisms and asthma [37]. In asthmatic subjects, an association between the length of the AAT repeat polymorphism in intron 20 of the NOS1 gene and levels of eNO has been reported [37].

Data on the heritability of eNO has not previously been published. In the present population-based sample of twins, genetic effects were found that accounted for $57 \%$ of the variation in eNO. Numerous studies have documented a strong association between atopy and eNO [7, 10, 32]. Since current knowledge indicates that atopy is genetically influenced [3-6], a common heritable origin for the two phenotypes may be suggested.

Since the present study was conducted outside the pollen allergy season, the only individuals likely to be tested during exposure are those with indoor allergies such as house dust mites or pets. Ideally, the modelling analyses should be stratified by twin-pair discordance and concordance for atopy. Such analyses would provide insight into whether genes and environments differentially mediate the relationship between eNO and AR contingent upon atopy. Although the current sample is not statistically powered for such stratified analyses, the association between eNO and AR is significantly larger (0.27) among those with atopy than among those without (0.07). Furthermore, inspection of the intra-class and cross-twin cross-trait correlations (eNO in twin 1 with AR in twin 2) in groups stratified by zygosity and atopy status of the pair (data not shown) suggests that genetic effects are highly important in explaining the relationship between eNO and AR among atopic subjects. Due to sample size limitations, these results should be interpreted with caution but warrant further investigation into the differences in the nature of genetic influences affecting eNO and AR when associated with atopy.

Compared with data on the genetics of atopy, data on the genetics of AR are scarce and incomplete. However, most current literature comprising data from twin studies, segregation analyses, linkage studies and genome-wide screens suggest genetic influences on AR [6, 20, 21, 38]. In 1984, Hopp et al. [38] conducted a study of 107 twin pairs aged 631 yrs who were tested for AR to methacholine. Heritability, calculated as twice the difference between the MZ and DZ correlations, was 0.66. An Australian study [20] using a population-based sample of nuclear families reported a much lower heritability $(0.30, \mathrm{SE}=12.3)$ for $\mathrm{DRS}$ to methacholine challenge than in the study by Hopp et al. [38]. Finally, another Australian study [21] of twins aged $8-18$ yrs included pairs who were concordant and discordant for current wheeze status. Although heritability was not estimated, odds ratios were consistent with genetic influences on AR as measured by responsiveness to hypertonic saline. In contrast, evidence of 
significant heritability for AR was not found. Heritability is a sample statistic and is expected to vary based on characteristics of the sample that are associated with the expression of genetic and environmental effects. For example, the present authors found significant main effects for smoking and atopy, but this does not reveal potential differences in the genetic and environmental variance components as a function of smoking or atopy status. Furthermore, differences in the sampling schemes, age group, prevalence and analytic methods between the Australian and Norwegian study could contribute to discrepancies regarding heritability estimates of AR. The Australian results based upon patient populations suggest that genetic effects may become expressed once asthma has developed, but may not be contributing to variation in AR when the disease is not manifest. If this is the case, then the heritability estimates may be sensitive to differences in disease prevalence in the investigated samples. The prevalence of atopy $(58 \%)$ and asthma (26\%) in the Australian study [21] was much higher than that observed in the general Norwegian population. Furthermore, whereas the present authors have studied young adults, children comprised a large percentage of the Australian twin samples [21,38]. AR is known to be significantly associated with age, with AHR being more prevalent in children than in adults [39]. Finally, AR is also influenced by smoking [40]. The present twin sample comprised 39\% current and ex-smokers, while the proportion of smokers in the Australian studies (not specifically stated) would be negligible or nil. It seems conceivable that mechanisms responsible for AR in adult smokers would differ from those in allergic children. Although the mechanisms are unknown, cigarette smoking reduces $\mathrm{eNO}$ and increases $\mathrm{AR}$, and it is reasonable to believe that cigarette smoking could influence the genetic environmental variance structure for both eNO and AR. Due to sample size restrictions, the present authors were unable to stratify the quantitative genetic analyses according to pair-wise smoking status. However, inspection of the twin intra-class correlations among the pairs, in which both twins were currently nonsmokers, revealed that similar conclusions to those reported herein would be drawn about the variance structure for NO. This is, that genetic effects may be slightly greater $(\mathrm{rMZ}=0.70, \mathrm{rDZ}=0.18)$ but are important for variation in $\mathrm{AR}(\mathrm{rMZ}=0.50$ and $\mathrm{rDZ}=0.03)$. Furthermore, the cross-twin cross-trait correlations $(0.35$ among the MZ and -0.07 among the DZ nonsmoking pairs) strengthens the conclusion that a genetic correlation explains the relationship between AR and eNO. The exposure effect of cigarette smoking on $\mathrm{NO}$ and $\mathrm{AR}$ should be investigated more thoroughly using a larger sample.

The present bivariate results suggest that common sets of genes account for the small but significant association between eNO and AR. Due to the fact that other studies analysing genetic covariance structures for asthma-related phenotypes have not included measures of eNO, the present results cannot be directly compared with other findings but are consistent with those based on a multivariate analysis indicating genetic effects common to asthma, atopy and AR [20]. Collectively, these studies are beginning to elucidate questions of aetiology and help guide linkage studies.

In conclusion, in a population-based sample of young adult twins, variation in exhaled nitric oxide was explained by genetic and nonshared environmental effects, whereas variation in airway responsiveness was best accounted for by environmental influences. Common genetic effects explained the small but significant association between exhaled nitric oxide and airway responsiveness.

\section{REFERENCES}

1 Los H, Postmus PE, Boomsma DI. Asthma genetics and intermediate phenotypes: a review from twin studies. Twin Res 2000; 4: 81-93.

2 Genes for asthma? An analysis of the European Community Respiratory Health Survey, Am J Respir Crit Care Med 1997; 156: 1773-1780.

3 Barnes KC. Atopy and asthma genes - where do we stand? Allergy 2000; 55: 803-817.

4 Heinzmann A, Deichmann KA. Genes for atopy and asthma. Curr Opin Allergy Clin Immunol 2001; 1: 387-392.

5 Holloway JW, Beghe B, Holgate ST. The genetic basis of atopic asthma. Clin Exp Allergy 1999; 29: 1023-1032.

6 Postma DS, Koppelman GH, Meyers DA. The genetics of atopy and airway hyperresponsiveness. Am J Respir Crit Care Med 2000; 162: 118S-123S.

7 Baraldi E, Zanconato S. The labyrinth of asthma phenotypes and exhaled NO. Thorax 2001; 56: 333-335.

8 Alving K, Weitzberg E, Lundberg JM. Increased amount of nitric oxide in exhaled air of asthmatics. Eur Respir J 1993; 6: 1368-1370.

9 Dupont LJ, Demedts MG, Verleden GM. Prospective evaluation of the validity of exhaled nitric oxide for the diagnosis of asthma. Chest 2003; 123: 751-756.

10 Jatakanon A, Lim S, Kharitonov SA, Chung KF, Barnes PJ. Correlation between exhaled nitric oxide, sputum eosinophils, and methacholine responsiveness in patients with mild asthma. Thorax 1998; 53: 91-95.

11 Crater SE, Peters EJ, Martin ML, Murphy AW, PlattsMills TA. Expired nitric oxide and airway obstruction in asthma patients with an acute exacerbation. Am J Respir Crit Care Med 1999; 159: 806-811.

12 van den Toorn LM, Overbeek SE, de Jongste JC, Leman K, Hoogsteden HC, Prins JB. Airway inflammation is present during clinical remission of atopic asthma. Am J Respir Crit Care Med 2001; 164: 2107-2113.

13 Dupont LJ, Rochette F, Demedts MG, Verleden GM. Exhaled nitric oxide correlates with airway hyperresponsiveness in steroid-naive patients with mild asthma. Am J Respir Crit Care Med 1998; 157: 894-898.

14 Silvesteri M, Spallarossa D, Battistini E, Brisasco V, Rossi GA. Dissociation between exhaled nitric oxide and hyperresponsiveness in children with mild intermittent asthma. Thorax 2000; 55: 484-488.

15 Peat JK, Toelle BG, Marks GB, Mellis CM. Continuing the debate about measuring asthma in population studies. Thorax 2001; 56: 406-411.

16 Crimi E, Spanevello A, Neri M, Ind PW, Rossi GA, Brusasco V. Dissociation between airway inflammation ad airway hyperresponsiveness in allergic asthma. Am J Respir Crit Care Med 1998; 157: 4-9.

17 Skloot G, Permutt S, Togias A. Airway hyperresponsiveness in asthma: a problem of limited smooth muscle 
relaxation with inspiration. J Clin Invest 1995; 96: 2393-2403.

18 Hoshino M, Nakamura Y, Sim JJ. Expression of growth factors and remodelling of the airway wall in bronchial asthma. Thorax 1998; 53: 21-27.

19 Duffy DL, Mitchell CA, Martin NG. Genetic and environmental risk factors for asthma: a cotwin-control study. Am J Respir Crit Care Med 1998; 157: 840-845.

20 Palmer LJ, Burton PR, Faux JA, James AL, Musk AW, Cookson WO. Independent inheritance of serum immunoglobulin E concentrations and airway responsiveness. Am J Respir Crit Care Med 2000; 161: 1836-1843.

21 Clarke JR, Jenkins MA, Hopper JL, et al. Evidence for genetic associations between asthma, atopy, and bronchial hyperresponsiveness: a study of 8- to 18-yr-old twins. Am J Respir Crit Care Med 2000; 162: 2188-2193.

22 Harris JR, Magnus P, Tambs K. The Norwegian Institute of Public Health Twin Panel: a description of the sample and program of research. Twin Res 2002; 5: 415-423.

23 Magnus P, Berg K, Nance WE. Predicting zygosity in Norwegian twin pairs born 1915-1960. Clin Genet 1983; 24: 103-112.

24 Harris JR, Tambs K, Magnus P. Sex-specific effects and body mass index in the new Norwegian twin panel. Genet Epidemiol 1995; 12: 251-265.

25 Kharitonov S, Alving K, Barnes PJ. Exhaled and nasal nitric oxide measurements: recommendations. The European Respiratory Society Task Force. Eur Respir J 1997; 10: 1683-1693.

26 Standardization of spirometry, 1987 update. American Thoracic Society. Am Rev Respir Dis 1987; 136: 1285-1298.

27 Quanjer PH, Tammeling GJ, Cotes JE, Pedersen OF, Preslin R, Yernault JC. Lung volumes and forced ventilatory flows. Report Working Party Standardization of Lung Function Tests, European Community for Steel and Coal. Official Statement of the European Respiratory Society. Eur Respir J, 1993: Suppl. 16, 5S-40S.

28 Sterk PJ, Fabbri LM, Quanjer PH, et al. Airway responsiveness. Standardized challenge testing with pharmacological, physical and sensitizing stimuli in adults. Report
Working Party Standardization of Lung Function Tests, European Community for Steel and Coal. Official Statement of the European Respiratory Society. Eur Respir J, 1993: Suppl. 16, 53S-83S.

29 Dreborg S, Frew A. Allergen standardization and skin tests. Allergy 1993; 48: 49-82.

30 Neale MC, Boker SM, Xie G, Maes HH. Mx Statistical Modeling. 6th Edn. VCU Box 900126, Richmond VA 23298, 2002.

31 Neale M, Cardon L, eds, Methodology for Genetic Studies of Twins and Families. Dordrecht, Kluwer Academic Publisher, 1992.

32 Henriksen AH, Lingaas-Holmen T, Sue-Chu M, Bjermer L. Combined use of exhaled nitric oxide and airway hyperresponsiveness in characterizing asthma in a large population survey. Eur Respir J 2000; 15: 849-855.

33 Langhammer A, Johnsen R, Gulsvik A, Holmen TL, Bjermer L. Sex differences in lung vulnerability to tobacco smoking. Eur Respir J 2003; 21: 1017-1023.

34 Plaschke P, Janson C, Norrman E, et al. Skin prick tests and specific IgE in adults from three different areas of Sweden. Allergy 1996; 51: 461-472.

35 Normann E, Plaschke P, Bjørnsson E, et al. Prevalence of bronchial hyper-responsiveness in southern, central and northern parts of Sweden. Respir Med 1998; 92: 480-487.

36 Henriksen AH, Holmen TL, Bjermer L. Gender differences in asthma prevalence may depend on how asthma is defined. Respir Med 2003; 97: 491-497.

37 Wechsler ME, Grasemann H, Deykin A, et al. Exhaled nitric oxide in patients with asthma: association with NOS1 genotype. Am J Resp Crit Care Med 2000; 162: 2043-2047.

38 Hopp RJ, Bewtra AK, Watt GD, Nair NM, Townley RG. Genetic analysis of allergic disease in twins. J Allergy Clin Immunol 1984; 73: 265-270.

39 Hopp RJ, Bewtra AK, Nair NM, Townley RG. The effect of age on methacholine response. J Allergy Clin Immunol 1985; 76: 609-613.

40 Schwartz J, Schindler C, Zemp E, et al. Predictors of methacholine responsiveness in a general population. Chest 2002; 122: 812-820. 